\title{
A POST-INDUSTRIAL PARADIGM FOR SUSTAINABLE ARCHITECTURE VIA AN OPEN SYSTEM MODEL
}

\author{
Y. GU \\ Victoria Research Laboratory, National Information and Communication Technology Australia (NICTA), Department of \\ Electrical and Electronic Engineering, The University of Melbourne, Australia.
}

\begin{abstract}
This paper critically analyses the unsustainable industrial pattern pervasive in modern architecture. From an environmental perspective, the aesthetic features of modern architecture range from environmentally de-contextual to environmentally irresponsible. In response to the imperatives of sustainable design in the built environment, the author explores a new paradigm via a model of open systems evolution, which is offered as a new paradigm for sustainable architecture. It reflects the worldview of post-modernism whereby the creativity and complexity of the universe is self-organised achieving the emergence of order out of chaos. Underpinned by evolutionary thermodynamics and complex systems science, a model of open systems evolution consists of mechanisms such as open systems adapting to a host environment via natural gradients to optimize resource distribution and minimize entropy production in the host environment. Following this model, the author proposes a conceptual framework for sustainable architecture that describes the ecological interactions of buildings with their natural environment in open thermodynamic terms, with active involvement of end-users in micro-climate control. These multiple communications between buildings, nature and end-users obey the laws of open systems evolution, in order to optimize the environmental performance of buildings while meeting the functional needs of end users, resulting in a sustainable symbiosis of architecture and nature.

Keywords: ecological architecture, evolution, the industrial pattern, intelligent design, open systems model, order, the post-industrial pattern, self-organisation, sustainable design.
\end{abstract}

\section{INTRODUCTION: THE UNSUSTAINABLE INDUSTRIAL PATTERN}

The industrial developmental pattern originated in Anglo-Saxon societies is responsible for national economic prosperity over the last 200 years. However, this pattern, which is still practised as a combination of industrialisation and globalisation, is now under serious question as to its universal generality. The following sections will critically analyse and identify this industrial pattern, its underpinnings of anthropocentrism philosophy and the neo-classical economic model, its consequential negative environmental impact and other limits and constraints. This pattern will be identified as an unsustainable pattern.

\subsection{The industrial development in Anglo-Saxon societies}

The industrial developmental pattern in force at today emerged in Britain during the Industrial Revolution in the mid of 18th century, then further expanded in North America to become the cornerstone of industrial mass-production, capitalism, globalization and great national wealth, in the 19th and 20th centuries. This is the industrial pattern now known as the Anglo-Saxon model [1], characterized by deregulation, privatization, labour flexibility and a high acceptance of risk.

The neo-classical economic model conceived by Adam Smith in the 18th century, claimed that industrial development, which effectively exploits natural resources as one capital and human labour as another, is a path to realizing economic prosperity in a more efficient and radical manner than in agricultural society [2,3]. Following this economic development, scientific progresses was achieved, since the use of tools was essentially required and encouraged; technology advances and a technical culture were dramatically accelerated $[4,5]$. All of these positive material progresses subsequently 
realized the evolution of human civilizations and liberation from intellectual, ideological, cultural, sociological and technological dimensions [2, 6].

In summary, the Industrial Revolution was a radical achievement of mankind, a transformation from agricultural society to industrial society, arguably the most significant jump in human history, liberating man from nature in a philosophy of anthropocentrism. A result of this industrialisation was modern urbanisation, modernization and mobility in Europe and North America earlier than in other continents $[2,7,8]$. Industrial development can be viewed as a victory for techno-centrism and anthropocentrism over the last two centuries. Human developments in science, industry and commerce have progressed rapidly, particularly, in the 20th century, the 'Age of Progress' [9].

\subsection{Anthropocentrism in Western industrial societies}

In Western civilisation, the debates on mankind's dialogue with nature can be traced back to the time of Plato. In the ancient world, nature was regarded with awe and fear. Natural disasters, earthquakes, hurricanes, volcanic eruptions were explained away as expressions of displeasure by the gods, while people were helpless in the face of its power. On the other hand, the ancient Greeks saw the world through a filter of mechanistic analysis and revered geometry as an indication of Man's superiority over nature, which prepared a pathway for the emergence of anthropocentrism in the Industrial Age.

After the major scientific discoveries of the 16th, 17th and 18th centuries, Western societies, with industrial structures and greed-driven economies, progressed relentlessly in a belief in conquering nature through science for the benefit of humankind [10]. Liberated by scientific progress is an obsession of anthropocentrism dominating in these societies. It was believed man was at the centre of the universe and nature existed for the convenience of humans; therefore, man is in his own omnipotence and ability to draw unrestrainedly on the earth's resources [7]. Legacies of this anthropocentric conceit include an aggressive growth of industrial 'conquer-the-earth' mentality and the absolute sovereignty of humans over nature. This radical philosophical change replaced the previous earth-centered philosophy when man stood in awe of nature, and alienated humanity from nature in an omission of nature's existence along with human progress in the industrial pattern.

In brief, Western societies since the canonization of anthropocentrism have neither the environmental appreciation, nor the ritualized observances; while nature seems to function as an infinite resource provider for their excessive exploration of energy and natural resources. By contrast, the dominance of anthropocentrism in Western societies led to a reliance on techno-centrism technocracy, profit-motivated capitalism and consumer-based culture. Nowadays, this anthropocentrism is thwarted by nature's revenge in the form of global warming, climate change, the spread of disease, and other natural catastrophes. In response, the industrialized societies responses are in two directions, humble cooperation and/or aggressive resistance.

\subsection{Neo-classical economy model for the industrial development}

As outlined above, industrial development has inherited the neo-classical model of economy derived from Adam Smith [11]. In this model, nature was viewed as little other than the source of free raw materials and a place to dump wastes of industrial production, while industrial products usually do not contribute positively to nature in another way, as shown in Fig. 1. Neither the health of natural systems, nor an awareness of their delicacy, complexity, and interconnectedness, has been part of the industrial design agenda $[2,12]$. Humans, by contrast, extract and burn coal in the 19th century and fossil fuels in the 20th century that have been deposited deep below the Earth's surface, supplementing them with energy produced through waste-incineration processes and nuclear reactors that create additional 


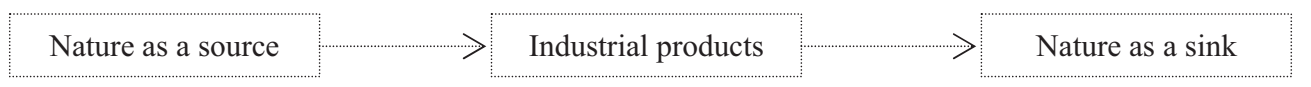

Figure 1: The metabolism of industrial production in a linear neo-classical model.

problems. They do this with little or no regard to harnessing and maximizing local natural energy flows. In addition, at the expense of the natural environment, consumerism in the industrialised economic society has accelerated the activities of economic prosperity and industrial production [13]. It is predicted, in the next 50 years, global economic activity is expected to increase roughly fivefold, while global manufacturing activity, energy consumption, and the throughput of materials are likely to rise threefold.

However, industrial development in a neo-classical economy model is challenged by contemporary economists in relation to concern with ecological consequences. For example, Daly [14] argues, that the human economy exists within a larger natural economy; homo-economy should be responsible, not just for the initial cost of production, but the cost of products' operation and decommissioning, the impacts upon all those other sites from where materials and energy were mined or will be buried, as shown in Fig. 2. To fail to account for the ecological costs of 'source', e.g. the natural resources, or the costs of disposing of 'waste' in natural 'sinks', is only to delude oneself that such costs are external to the economic system. This idea is extended by Hawken et al. [15] as the world's economy being within the larger economy of natural resources and ecosystem services that sustain us. In summary, ecological sense should no longer be missing in the economical system.

\subsection{Environmental crisis questioning on the industrial development}

Since the late 20th century, this industrial development pattern has been transported to developing countries along with the economic globalisation. Accompanying this industrial and economic globalization are a number of significant questions. First, argued by the author, the industrial pattern is incompatible with many regional contexts. The continent of Asia, for example, is characterised by large populations and hyper-density human habitat. This context is incomparable with the compact model of the United Kingdom with limited geographic resources and small population scale, and also incompatible with the spread-all-over model of the United States of America with abundant geographic resources but relatively small population scale. Furthermore, the exacerbating environment impacts such as global warming and climate change, caused by the consumption of fossil fuel in industrialisation, urbanisation and agricultural activities, indicate this developmental pattern is environmentally unsustainable at the global scale, threatening the long-term sustainable human habitat on the planet.

Specifically, by the early 1990s, citizens of nearly every nation on earth began to experience, either directly or indirectly, unusually severe environmental changes in the form of heat waves, soil pollution, global droughts, massive crop failures, nuclear power plant meltdowns, oil spills, and increased incidence of disease, limited food and water supplies, lead in gasoline, tropical rain forest degradation, nuclear waste pollution, lethal viruses, etc. All of this has created a feeling of impending doom and anticipation of a coming catastrophe in many people. In brief, it is the industrial countries that bear most of the responsibility for global warming and climate change; however, the effects are felt acutely in every country and particularly in developing countries. In addition to global climate change, the profligate consumption of energy and natural resources used in support of industrial development has resulted in the depletion of limited energy and natural resources on the earth. Industrial development enlarges the ecological footprint [16], through successive demands on natural resources 


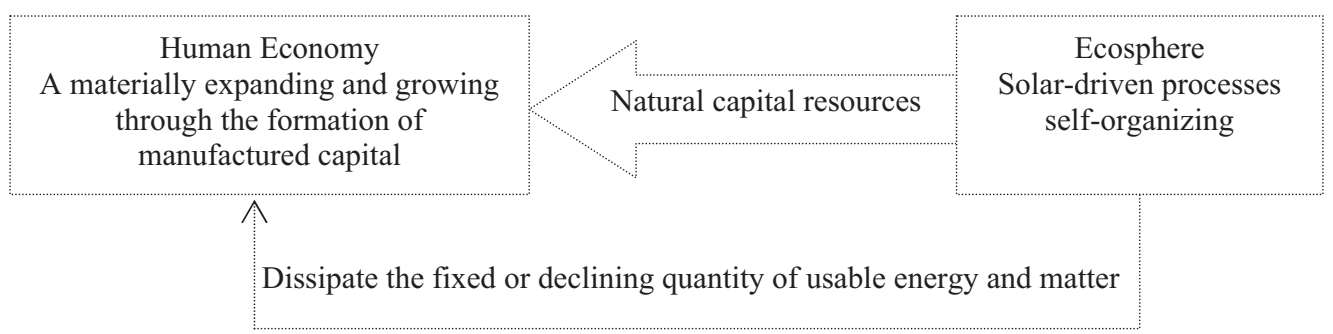

Figure 2: Ecological interrelations of homo economy and ecosystem.

such as water, land and energy. A comprehensive study of the complex relationships between industrial development and natural resources and an analysis of the environmental price of industrial development can be found in Commoner [17].

In general, the current issues raised by development which follows the modern industrial pattern range from resource degradation, to population growth and agricultural limits leading to global famine, pollution of air and water, the disastrous potential climatic effect through the concentration of greenhouse and ozone-depleting gases in the atmosphere [3]; furthermore, cross-national tension among industrialised countries and un-industrialised nations, intellectual and ethical progress, economic crises and other sociological decay has emerging since the latter part of the 20th century, all of which have been essentially overlooked in the pursuit of economic prosperity. In brief, at both regional and global levels, these so-called advances in industrial development are increasingly viewed as the enemy of true progress by the majority of environmentally sensitized people. Anthropocentrism, i.e. humanity holding a privilege of man's sovereignty in the universe, is criticised as having violated its basic ethical responsibility of 'each generation's obligation to meet its needs without jeopardizing the prospects for future generations to meet their own needs' [18].

\subsection{Summary: the industrial pattern is environmentally unsustainable}

It is argued that societal progress based on the existing industrial development pattern, which has prioritized industrial growth and economic prosperity in the western industrial societies over the last two centuries and which still colonizes world cultures and the global environment, has been achieved at the expense of excessive exploitation of energy and natural resources while overlooking the negative impacts upon the natural ecosystem. Thus, this modern civilization is environmentally unsustainable. The rules and patterns of industrial development do not provide a sustainable basis for further progress of humanity over the long term. Hence, an urgent task is to constitute a new sustainable pattern that is environmentally responsible, contextually compatible and universally applicable.

\section{IDENTIFYING THE CONCEPT OF SUSTAINABILITY}

The term sustainability has been adopted, after a long series of institutional initiatives, primarily guided by the United Nations, and is characterised as a compromise between the 'growth' and 'nongrowth' factions of the environmental movement of the late 1960s and early 1970s [19]. In particular, the energy crisis of the early 1970s, caused when the OPEC countries placed an embargo on oil exports, raised public consciousness about energy use and led to developments in energy conservation and the consideration of alternative energy sources, such as wide power [20]. On the grass-roots scale, the environmental movement was initiated in the late 1960s by a generation that rejected the 
excesses of the consumer society and called for an end to unrestricted economic growth [7, 19]. In 1987, an initial official definition of sustainable development was launched in the Brundtland Commission [21] which states: 'development that meets the needs of the present without compromising the ability of future generations to meet their own needs'. At the 1992 Rio Earth Summit, sustainable development was defined as 'development which fulfils current needs without compromising the capacity of future generations to fulfil theirs'. This principle of suitability was enshrined and formulated in the Agenda 21 [22], as a common framework of action for all countries to achieved sustainable development in the 21 st century.

\subsection{An integrated proposition of sustainable design}

Physicist Jaynes [23] argues in decision theory that failure to judge one's own loss function correctly is one of the major dangers that human face, and the state of nature tomorrow might be influenced by our decision today. Responding to increased environmental awareness and recognition of the fragility of the planet, social inequities and human rights, it is argued that sustainable development addresses three interrelated areas simultaneously: environmental protection, social equality and justice, and economic viability. At an abstract level, a general exploration of these complex and problematic issues facing humanity is a path to constructing a human habitat in harmony with the natural environment while meeting the demands of social and economic developments in a long term, rather than a short gain for the present generation only.

In brief, sustainable development is an integrated spectrum composed by temporal, social, economic, environment and human dimensions, formulated in Fig. 3. Confronting the current environmental crisis, a deteriorated environment would be unable to support the social and economic demands and to sustain human well-being. Thus, the natural environment is recognised as the centre theme of sustainability with the highest priority. Specifically, a growing recognition of sustainable development [24] is that long-term economic and social vitality depends upon more efficient, effective use of natural resources, coupled with improved human and environmental health, as shown in Fig. 4. The challenge is how to sustain and transfer the developments from the past, through the present, to the future, with the recognised environmental problems threatening the human survival.

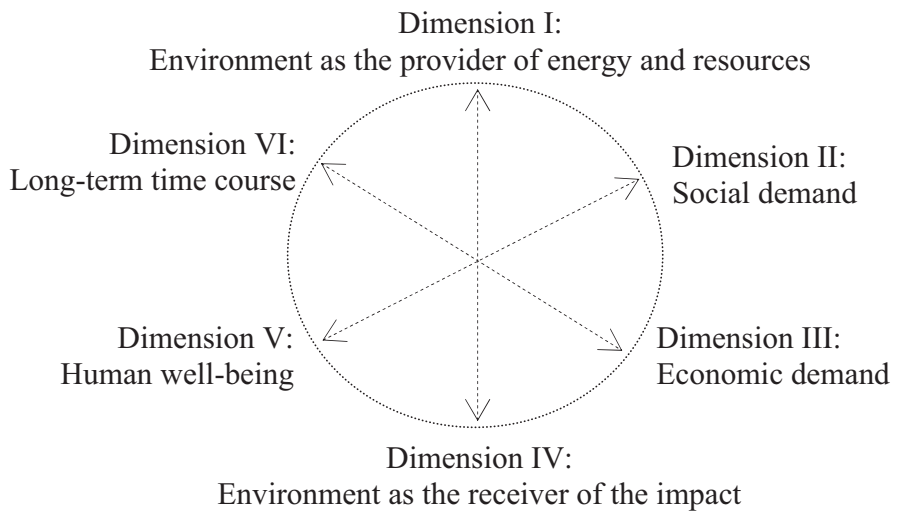

Figure 3: Full dimensions of sustainable development as a complex system. 


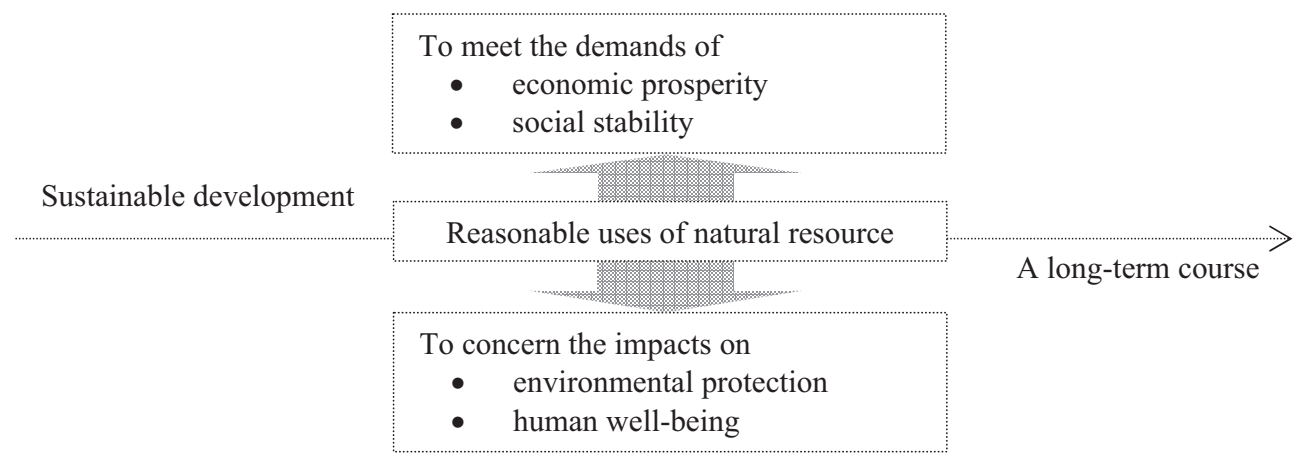

Figure 4: Sustainability transfer in a long-time course.

\subsection{Technological innovations to meet the challenges of sustainability}

From Fig. 4, it can be seen that sustainability is a dynamic process affecting all aspects of human life, resolving the conflicts between the various competing goals, which involves the simultaneous pursuit of economic prosperity, environmental quality and social equity as three dimensions or triple bottom lines with the resultant vector being technology. These complex communications of multiple-dimension sustainable development is generalised in Fig. 5, including technological, ecological and environmental, economics, and socio and ethical-cultural dimensions.

In response to these complex compositions of sustainability, technological innovation towards sustainability [25] aims at designing, purchasing, or adapting facilities according to environmentally responsible principles, e.g. minimizing consumption, maintaining human satisfaction and minimising negative environmental impact, which must be evaluated in terms of the materials being constructed, used, refurbished and reused. For example, the Environmentally Responsible Facility (ERF) Matrix is developed to encompass all stages of facility operations and all relevant environmental concerns, corresponding to the life cycle of a generic facility. Another technological breakthrough towards sustainability is the constitution of Environmental Sustainability Index (ESI), designed by Yale Center for Environmental Law and Policy and Center for International Earth Science Information Network, to assess environmental sustainability in countries with integrated criteria of environmental, human and social components [26]. Life cycle assessment is another sustainable technical tool for environmentally conscious design, regenerative technology and industrial ecology.

\subsection{Summary: a leap from the linearity of industrial pattern to the complexity of sustainability}

From the philosophical viewpoint of classical Platonism, concerning space, time and man, sustainable development is hypothesized as a development at a 'decent' rhythm, in a humanly acceptable and environmentally friendly pattern, in order to reach the complexity, richness, diversity and sustainability for the long term. An alternative sustainable pattern is proposed to meet the complex demands of sustainable development, in a leap departure from the previous economic dimension of the industrial pattern only to the multiple temporal, social, economic, environmental, cultural and technological dimensions. This alternative pattern can be proposed as a post-industrial pattern, distinguished from the industrial pattern overlooking the complexity of sustainability. 


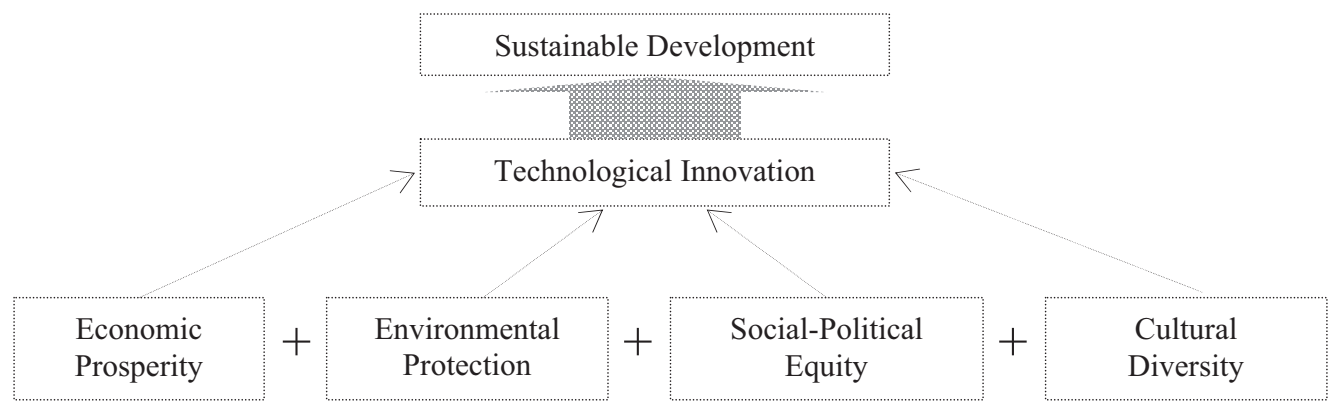

Figure 5: Sustainability in a spectrum of multiple dimensions.

\section{MODERN ARCHITECTURAL DESIGN IN THE INDUSTRIAL PATTERN}

Modern cities since the Industrial Revolution in the 19th century consist of human inhabitants, means of industrial production and commercial activities, transport infrastructure of roads and rail, energy infrastructure, communications infrastructure, open space and other public facilities. In modern urban design and planning with features of rationalism, functionalism and mechanism, the diverse demands of urban compositional facilities are met by substantial consumptions of energy and natural resources. In consequence, cities are operated like combustion engines in sprawl, dispersal and fragmentation, producing great amounts of pollution emissions. Not only cities designed and developed in this industrial pattern, but also buildings in the Industrial Age have been conventionally designed with severe consumption on energy and natural resources, with the consequences of negative environmental impact on the natural environment and human well-being. The features of modern architecture embody environmental de-contextualisation, without any environmental awareness and sensitivity to the natural ecosystem. In brief, both the natural environment and the built environment have been drastically affected, leading to climate changes on a global scale and deteriorating liveability on an urban scale. The authors argue this industrial pattern designed in modern architecture as environmentally unsustainable.

\subsection{The industrial contexts of modern architectural design}

The historical background of modernism architecture is the Industry Age from the late of 19th century to the 20th century. As argued above, this age is charactered of anthropocentrism in a mechanistic view of humanity's superiority conquering over nature, a neo-classical economic model, industrial technology, and scientific progress via reductionism [2]. Specifically, the scientific dominance over the last two centuries was Newtonian and Cartesian science, in which the materiality of nature, representing disorder, chaos, and unpredictability, was ignored and devalued [6]. Furthermore, the features of modern science include reductionism, mechanism, linear determinism, predictability, and a quest for and love of simplicity [5, 27-30].

Within this industrial, social, economic and scientific background, architecture was defined as an independent and intervention object in its context, a manifesto of techno-centrism and anthropocentrism, a celebration of a progress in industry and technology. As hailed by the great Modernist pioneer Le Corbusier in 1923: 'there exists a new spirit, Industry, overwhelming us like a flood which rolls toward its destined end, has furnished us with new tools adapted to this new epoch, animated by the new spirit' [31]. 


\subsection{Aesthetic features of modernism design}

In particular, modernism architecture in Germany relied upon the quality, precision and level of technological advancement, together comprising an effective tactic for conveying the message of neo-economic abyss [19]. In the 'advance' toward a scientific model, the 20th century's architectural modernism set into motion in a rational program of simplification and objectification [30]. The logic of modernism shares a fascination for abstraction and minimalism, in the aesthetic criteria of pure and simple, inspired by both abstract art $[6,32-35]$ and reductionism in modern science. Consequently, modernism aesthetic features include abstraction, functionalism, mechanism, technically expressive, etc.

Le Corbusier was one of the most eloquent celebrants of the rationality of the machine, the machine aesthetic of purism [19]; the legendary slogan 'less is more' was articulated by Mies van der Rohe in the programmatic ban on ornamentation to the geometric abstraction of primary forms [29]. The language of architecture is dominant by standards, types, and norms [32]. Perceivable detail is missing in the modernism design in the Industrial Age, in contrast to Medieval and Renaissance architecture [35]. In practice, architecture has been designed as a machine for function and utility in mechanical logic $[8,36]$, i.e. city as a machine for living and working, buildings as machines for living, an equation between a combustion engine and a spiritual vision for shelter, committed to shape-making, space-making in formalist and functionalist invention [10]. Since 1970s, the progress of industrial technological advantages was synonymously expressed in high-tech features, i.e. exposed structural systems, vast expanses of plate glass, and cantilevered, tilted, or skewed steel trusses.

However, the monotony of architectural language which is derived from modern paradigm of industrial machine is criticized in its attempt to impose universal design solutions on an infinite number of local conditions and customs $[2,13]$ The spatial diversity, natural and cultural diversity have been lost in modernism design, which results in less variety and greater homogeneity [29]. The homogeneity in modernism are to be read in the metaphors of the collaboration of Mies van der Rohe with the Nazis, the compromise of Le Corbusier with Mussolini and Petain, and of Terragni with the Fascists [32].

In brief, since the late 19th century and the early 20th century, modernism architectural design has been developed in response to its sociological, economical, cultural, scientific and technological contexts. However, the monotony and simplicity of the modernism design agenda is inadequate to meet the complexity of societal imperatives. In particular, from the environmental perspective, the problem of environmentally de-contextualised in modernism architecture is represented as environmental unawareness, ecological dependencies and negative environmental impacts upon the natural environment, to be specified in the next section.

\subsection{Environmentally de-contextualised modern architecture in the industrial pattern}

Argued by architectural theorist Venturi [37], the classical concept of architecture does recognise context within composition, i.e. the building as a system of relationships of geometric shapes; it is context gives a building's expression, to which the whole composition of building may possess different degrees of articulation. However, in its concept of universality lack of emphasis on natural and architectural setting, the modernism approach disregards context from an organic standpoint, which results in narcissism in the environmental sense [10]. In response to this legacy, one of contemporary problems in architecture [37] dating back to the Beaux Arts Institute of Design is that the building could be designed only for itself, which frequently lacked of indications of buildings' setting, or at best indicated merely the physical dimensions of the site. More drastically, the International Style 
involving de-contextualised abstraction which is independent of location was the basis of strategies to unify architecture and urban planning in the Modern Age [32]. In brief, modernism abstracts is away from contextual relationships [27].

This shortage of environmental awareness in modernism architecture and urban design is recognised as the reason for the environmental degeneration in the 20th century. Observed in cities around the world is the absence of environmental commitment in architecture, while associated with industrial imagery and technically driven design style in functionalism and formalist to meet the demand of utilitarian and economic imperatives of modernity $[6,29]$. In addition, the adoption of wasteful technology by using ecologically offensive materials [7] and the excessive dependence of fossil fuel are ecologically irresponsible, which have caused incalculable environmental damage [10].

\subsection{Environmental impacts of buildings over the life cycles}

In particular, over the life cycles, buildings have been conventionally designed in the linear industrial pattern influenced by the neo-classical model [11]. In this pattern, the metabolism of buildings is supported by profligately consuming energy and resources as the input from the natural ecosystem, consequently producing considerable waste emission to the natural ecosystem, as shown in Fig. 6.

In detail, a building's ecological dependence is composed by the energy and natural resources use from the natural ecosystem, the amount of which depends on buildings' position, shape, structure, materials and energy needs. Specifically, three major requirements of energy and natural resources in buildings are generalised as follows:

1. The construction of buildings such as the production of building materials by exploiting energy and natural recourses of water, materials, land, wood and fossil fuel [7].

2. The operation of mechanistic services for the micro-climatic control within buildings [5], by the passive use of energy and resource use, i.e. sunlight, air circulation, landscaping, water and materials; and

3. The positive use of electrical energy and other energy for lighting, ventilating, heating and air conditioning, HVAC system [38].

In other words, the complex fluxes of energy and natural resources in a building start from raw materials, processing into primary energy, converting into secondary forms of energy such as electricity or district heating, continuing in the form of energy used by the end-consumers as supplied energy, then distributed into domestic technical installations as usable energy and a variety of grey energy, until the final demolition and removal of rubble. These fundamental ecological interactions

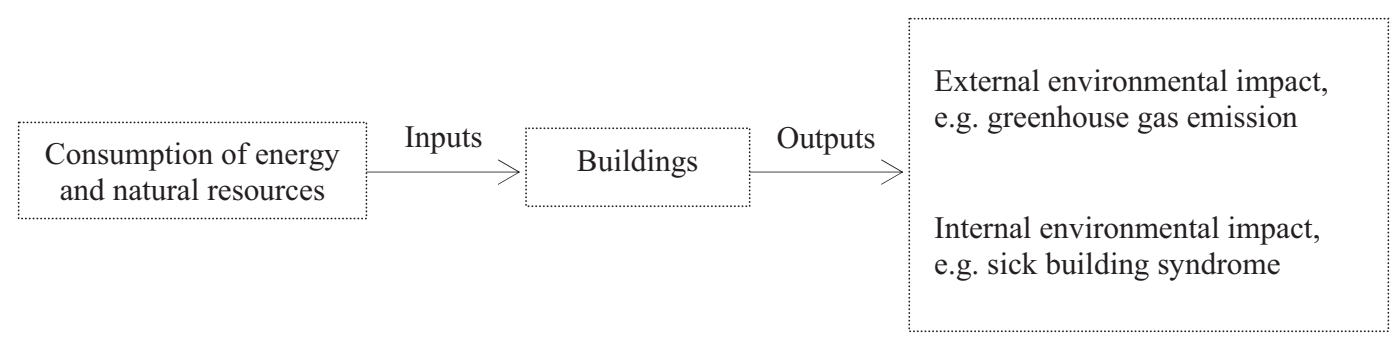

Figure 6: The metabolism of buildings and cities in the linear industrial pattern. 
of buildings with the natural ecosystem can be generalised as buildings' environmental performances and impacts upon the context of the natural ecosystem, which have substantially contributed to the degradation of the built environment.

\subsection{Questions on modern architecture from the environmental sustainable perspective}

The severity of environmental impact, in particular, has shed a light on doubting the relevance of modern architecture designed in the industrial pattern to the contemporary age [6], while the original visual factor becomes marginalized [36]. To enhance a building's environmental performance and reduce its unsustainable environmental impact, questions for the building industry are addressed from the perspectives of ethical concern, design motivation, principle, concept and technique, as follows:

1. Question on ethics: why human habitant by buildings is designed in such industrial mechanics, intervening into nature by consuming so much energy and resource and producing such great amount of negative environmental impacts?

2. Question on the sources of energy and resources use: is it possible to adopt the mechanics of buildings in such a way by using other energy, i.e. biomass and solar energy and resources, to replace fossil fuel, for less, neutral, and even positive environmental impact?

3. Question on the pattern of energy and resources use: how to improve the linear metabolism of energy and resource for buildings in an alternatively efficient manner towards sustainable environmental performance?

4. Question on technologies on environmental management: to facilitate environmental management in the built environment, which technologies and techniques can be devised to effectively indicate, monitor, assess, adapt and optimize the environmental performance of buildings over the life cycles?

5. Question on design configuration: how to configure environmental constraints, i.e. ecological dependence and environmental impacts, as essential design criteria for environmentally responsive buildings and cities?

\subsection{Summary: the simplicity of modernism unable to meet the complexity of sustainability}

Despite all the progressive features, such as aesthetics and technologies in the manner of reductionism, functionalism and utility mechanism, modernism architectural design, which was institutionalized as dominant over the Modern Industrial Age, is nowadays criticised as being incapable of conceptualising the diversity and complexity of imperatives embedded in the social, economic, cultural, environmental contexts of the Post-Industrial Age. The ruptures and the dynamism of the urban environment in this age consist in an integrated picture of artistic aesthetics, cultural diversity, societal change, human psychology and the growing significance of eco-psychology $[10,12,34,39]$. In particular, challenged by the present global environmental crisis, depleted natural resources and increasing world population, environmentally responsive architecture or sustainable architecture is embraced with the highest priority over other issues [10].

Therefore, it is necessary to expand the inadequacy of modernism architecture into an alternative complexity of post-modernism. Accordingly, trans-disciplinary knowledge and a systematic approach are argued to be necessary in architectural design [12], to reconcile ecological, economic, social and other implications for a long-term achievement of sustainable development, to mitigate the environmental crisis, to sustain the natural resource of the world, and to enhance the quality of human inhabitation. 
To meet the complexity of sustainability, architectural innovations will range from the scales of megalopolis to the choice of construction systems.

\section{A SHIFT TO THE POST-MODERNISM}

Prior to the environmental crisis and economical crisis, which have emerged in the late 20th century and the early 21st century, is a cultural crisis in people's daily life in the Western industrial society, complaining of losing its orientation, disintegrating into angry fragments for more than 50 years [29]. Modern science is accused of only producing partial truths, while traditional religion, as another principal means to explain ultimate truths, is also inadequate in interpreting and revealing the complexity of the universe. Meanwhile, the consequential diversity and complexity of industrialization and modernization is far beyond the capacity of the old paradigm of modernism. In this setting, complexity science has grown over the last decade, in line with the emergence of post-modernism, to provide a new paradigm for ensuring sustainable progress not only in an environmental sense, but also in social-cultural-economic sense.

\subsection{A new worldview proclaimed by the complexity science}

The definitional authority of complexity science was located indisputably in the gravitational fields of cybernetics, computer science, information technology, quantum physics, fractals theory, chaos theory, catastrophe theory, emergence theory, nonlinear dynamics theory. In contrast to the modern science of simplicity in reductionism, mechanism, and linear determinism, and to the traditional cosmological viewpoint of gradual and continuous developments of the universe, the evolution of the universe is interpreted in the complexity science as phase transitions in spontaneous change and quantum leap [29], and the creativity of the universe as self-organisation for organised complexity, the order of the universe [40].

In complexity science, the unpredicted and underdetermined aspects of the universe are interpreted as phase transitions of dissipative structures [33], i.e. the spontaneous change or the emergence of new organisations in a dissipative structure, due to external energy, heat and information, and the internal pressures. Such a cosmogony orientation of nature going through sudden phase transitions in organisation discloses the fundamental principle of the universe in increasing complexity and higher levels of organisation, creative, open, dynamic, surprising in its active energy, its growths and sudden leaps, its beautiful twists, curls and turns, and its catastrophes [29].

Examples of complexity and self-organisation can be found in all living organisms, and even super-organisation, such as a beehive, city or any type of social organisation [41]. Theoretically argued in 'Gaia theory' in earth science [42] and cellular automata in biological science [43], every being, from the atom to the nation and the galaxy, has a quality of self-organisation and a degree of freedom, the ability to reorganise itself through feedback. Each is balanced in a delicate zone for passion and reason on the edge between too much order and too much chaos; this boundary condition is the place of maximum complexity and computability; everything in nature and culture is pushed toward this creative edge by evolutionary pressures, by natural selection and internal dynamics. The unpredictable, abrupt aspect of this post-modernism worldview also shows that violence and mass-extinction are essential parts of evolution [29].

\subsection{Redefining the complexity of architecture in the post-modernism}

This new worldview of the post-modernism indicates a paradigm shift from the simplicity of the modernism in the Modern Industrial Age to the complexity of post-modernism in the Post-Industrial 
Age. It rediscovers aesthetic and spiritual meanings of nature, which is denied by modernism in mechanism, linearism, and reductionism. The human society is thus meant to be self-organizing, in which the mind and culture are typical of their creativity. One of driving forces for human evolution is argued as human desire for learning [29], mankind evolving and progressing forward high level civilisation above ignorance. Hence, the fundamental intellectual and philosophical interrelation of man and nature is meant to progress to the extent far beyond the limited, inadequate modernism.

In response to these revolutionary progresses in science, the spirit of culture and the aesthetics of life, architecture is also meant to reflect this new world view of the creativity of universe, a departure from the modernism. Particularly, confronting with the environmental crisis since the late 20th century, architecture enriched by this new worldview is hypothesised to be able to confront the challenge of environmental sustainability, i.e. buildings to be earth-friendly to alleviate environmental problem and to restore the natural ecosystem. This post-modernism movement towards sustainable built environment will liberate architectural design from the constraints of existing industrial technology, politics, and economics, changing the architectural profession's basic philosophical and aesthetic values, design pattern and methods, concept and motivation [10, 13].

Architectural theorist Venturi [37] was one of promoters of complexity in architecture. The principle concern for the re-establishment of complexity is to restore to both art and everyday life the rights deprived of by the strategies of simplifying systematization that governed the abstract model of architectural design prevailing in modernism. The first stage of complexity in architecture is argued by Venturi as the collage of pre-existing, well-known solutions, the manipulation of classicism or any familiar ground. A recent argument on the complexity of architecture by Hagan [6] is inclusive of topology, morphology, biology, geology and complexity currently swarming amongst the architectural intelligentsia. Another theoretic standpoint by Vrachliotis [30] argues three lines of development on the complexity of architecture: a gestalt-psychological line, a cybernetic line and a biological-algorithmic line.

\subsection{Summary: the complexity of post-modernism to meet the complexity of sustainability}

The era of post-modernism has emerged since the late 20th century, along with a series of revolutionary advances in sociology, ecology, information technology and science, shifting from the reductionism simplicity of modernism science to the organised complexity of the post-modernism, revealing the new worldview of creativity of the universe. With this paradigm shift, the challenge of sustainable design in architecture will be possibly resolved, by expanding the design agenda, by absorbing progress in knowledge and technology. In specific, in the new Age of Information and Ecology of the 21st century, with the contextual influences of sociology, information technology and scientific progress, reinforced by earth-centralism, architecture will be rapidly changing to be of an environmental responsibility, to alleviate environmental problem and to restore the natural ecosystem.

\section{A PARADIGM OF NATURE FOR SUSTAINABLE DESIGN}

In general, nature is primary, metamorphic, and endlessly ambiguous; it offers a universal source and reservoir of ideas and symbolism in the arts, imagery for infusing architecture with a more relevant visual content [35, 44]. In addition, the profusion of evocative subject matter associated with nature consists of its comfortable scale relationships to the human body, the complexity of its structure, and the science describing its dynamic processes.

In contrast to the paradigm of machine in modernism design, nature has been appreciated as an inspirational and methodological paradigm in architectural design. The diverse implications of the paradigm of nature lies not only in spiritually symbolic value of harmony between man and nature 
in vernacular architecture, but also in a morphological sense, such as the aesthetic form, structure and function in organic architecture, and in information sense, such as the dynamic mechanisms of selforganisation, optimisation, evolution and generation in evolutionary and cybernetic architecture, and more importantly, in an environmental sense, such as the metabolism of nature for its diversity and vitality, self-organisation and evolution mechanisms for its sustainability.

\subsection{A scientific paradigm of nature for sustainable design}

In the Age of Information and Ecology since the mid 20th century, sustainable design is argued to be empowered by the progresses in modern science for the exploration of advanced strategies, propositions and technologies which are both ecologically responsible and symbolically communicative $[10,13,28$, $29,40]$. For example, studies in modern ecology, biological and thermodynamics sciences, the complex patterns, methods and mechanisms of organic systems introduces how an organism operates as a selfcontained, self-sufficient and self-organising system fit into the niche of nature for an ecological sustainability, vitality and resilience. In addition, the specialties of nature [44] as an integrated and selfcontained living ecosystem are composed of its sustainable prosperity, its perpetual metabolism, no-waste emission, and the principles of self-organisation, optimisation and the thermodynamic laws.

In brief, nature provides a scientific paradigm as a methodological backbone to establish the concept and framework of sustainable architecture in the context of the natural environment. This scientific paradigm opens a new horizon for environmentally sustainable design in architecture, which calls for a conceptual, aesthetic, motivation, objective and philosophical departure from modern architectural design in the industrial pattern. For example, it advocates a philosophical underpinning of eco-centrism to replace anthropocentrism in sustainable design, for environmental symbiosis of architecture and nature.

\subsection{A hypothesis: an intelligent model for sustainable architecture in the paradigm of nature}

As generalised in the concept of sustainability, both human demands and environmental concerns of the natural ecosystem must be integrated into sustainable design. In addition, sustainable architecture is proposed to reflect the new worldview of post-modernism, i.e. self-organisation and evolution for the emergence of order. Hence, in hypothesis, an alternative proposition for sustainable design is to systematically integrate man, nature and innovative technology into the art of sustainable architecture, which follows the paradigm of the natural ecosystem, in self-organisation and evolution for the sustainable symbiosis of architecture and nature. Specifically, buildings are hypothesised to be able to self-organise their ecological interaction with nature in the form of energy and natural resources as inputs to meeting the micro-climate demands from the end-users of buildings, and to adapt and optimise their pollution emission as outputs, in feedback towards a maximum efficiency of energy and natural resources and minimising their negative environmental impacts on the natural ecosystem.

In other words, by applying the intelligence of nature, the metabolisms of buildings will be improved for an ecologically sustainable symbiosis with nature, in a conceptual analogy of buildings like trees and cities like forests [2], with structure, material and energy associations. This model can be generalised as an intelligent model of buildings in the metabolism of living organisms in the natural ecosystem. This is a holistic sustainable design scheme [45] proposed to embrace the dimensions of man, nature, and buildings, optimising the environmental interrelations of buildings with the natural ecosystems, and human accessible via information communication technology. To realise this hypothesis of an intelligent model for sustainable architecture, a more concrete framework from natural sciences is essential, specified in the following section. 


\section{OPEN SYSTEMS MODEL FOR SUSTAINABLE DESIGN}

In natural science, the laws of thermodynamics are the fundamental laws governing energy use and transfer in systems. Classical formulations of the Second Law of Thermodynamics introduce the irreversibility of entropy increase in isolated systems, i.e. degradation of energy, waste and unavailable energy during thermodynamic transformations. However, a striking modern statement of the Second Law as it applies to open systems generalises not only the irreversible entropy increase as the arrow of time, but also the evolution of open systems for the emergence of order. Open systems evolve as dissipative structures transferring far-from-equilibrium to stability and compatibility with the host environment, re-distributing material and energy within the system. This open thermodynamics model provides a scientific framework to interpret, analyse, adapt and optimise the environmental performance of buildings as thermodynamic exchanges, including both energy and resource use and environmental impacts upon the natural ecosystem. For a more detailed introduction to open systems models and the various mechanisms, including self-organisation and evolution see [45].

\subsection{A theoretical framework of evolution: self-organisation and optimisation for order}

The fundamental mechanisms of open systems evolution via the Second Law of Thermodynamics are composed of entropy gradients interacting with the host environment through microscopically self-organising structures for an optimal distribution of energy, matter and information in feedback loops, to increase the complexity of open systems, and to minimise the entropy production into the host environment, leading towards the emergence of order, i.e. a macroscopic compatible interrelation of the open system and the host environment. The evolution of open systems in feedback, as shown in Fig. 7, implies a method of 'evolving by learning', i.e. an open system learns from the previous experience to evolve and attain a desirable outcome, thus the system evolves smoothly from the past to the future for its sustainability. Furthermore, the open systems entropy balance equation implies the rates of variables determine the emergence of desirable outcomes such as order.

\subsection{Universal generality and implications of open systems model}

The Second Law of Thermodynamics for open systems holds significant implications for the formulation and interpretation of emergence phenomena and transformations in the natural sciences, and by analogy in the social sciences. Archetypes of open systems can be found in living organisms, the ecosystems, the universe, physical matter, social society, human life, etc., which can be interpreted in terms of self-organisation and evolution, the emergence of order, and the production of entropy from the model of open systems evolution. For example, the origin of organic life is assumed to be open thermodynamic systems in biology; the formation, organisation and degradation of matter in material science are entropy phenomena in nature; the creation and creativity of the universe is open systems evolution in cosmology; the dynamics of human psyche is closed or open systems in psychology; the evolution of human society is recognised as open systems evolution in sociology. In brief, the generality of open systems evolution implies a new worldview: the creativity and complexity of the universe is generated by its evolution and self-organisation as an

open system; and the model of open systems evolution is a fundamental scientific mechanism for the adaptation and optimisation to the emergence of order.

\subsection{A post-industrial pattern for environmental sustainability}

The study of thermodynamics was initiated in the Industrial Age, which accelerated the thermodynamic conversion of natural resource into mechanical work demanded by industrial 


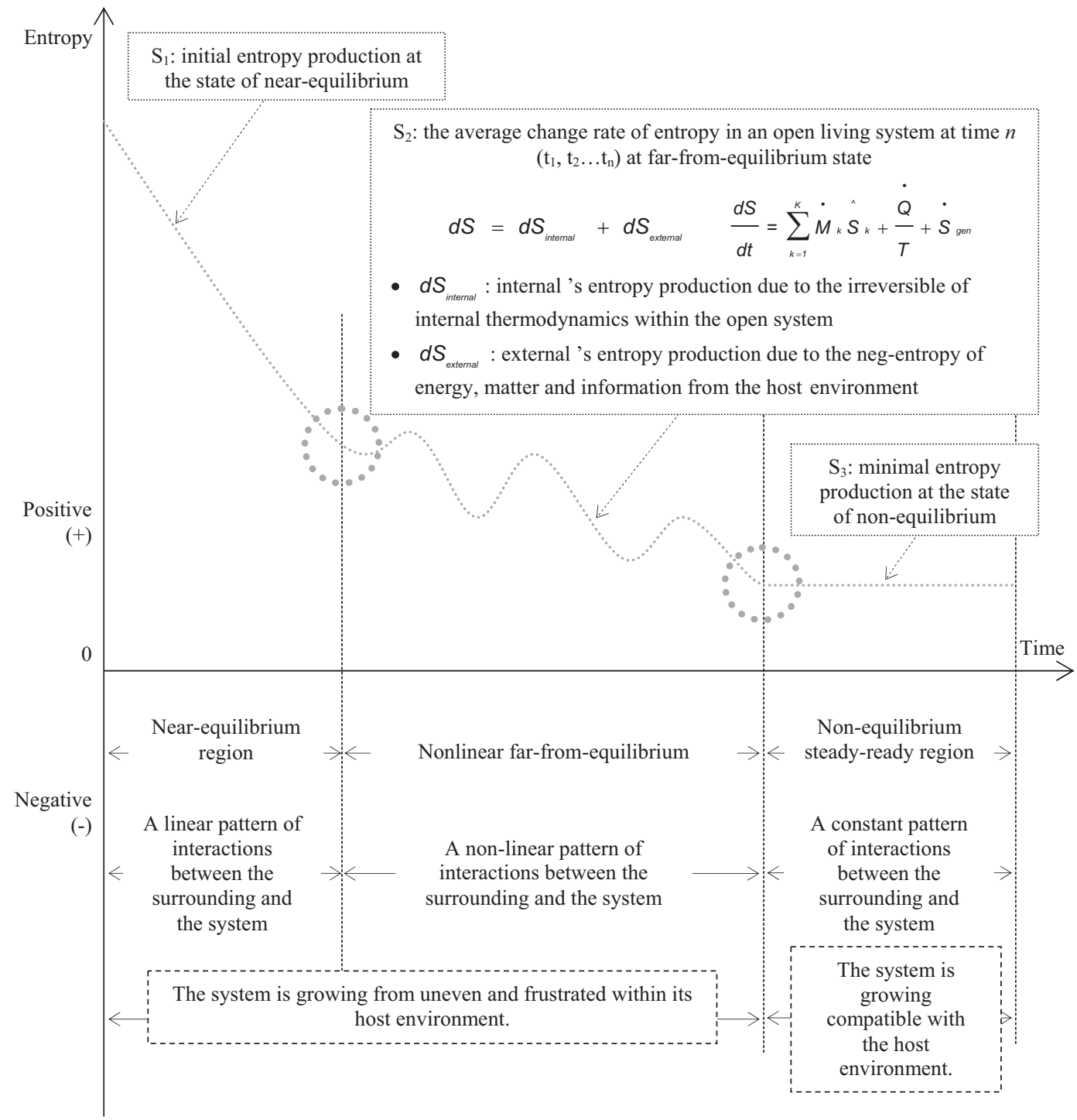

Figure 7: Three transitional phases of an open system evolution.

progress. However, the technologies of energy use and the choices of energy use in the early industrial pattern [46] have induced the environmental crisis which is emerging in the late of 20th century. As argued by physicist Frederic Keffer [47], 'the early industrial revolution involved energy, but the automatic factory of the future is an entropy revolution'. It suggests, in terms of the Second Law of Thermodynamics, the initial industrial pattern follows the pattern of closed systems or isolated systems, without an effective mechanism to optimise the energy and materials resources use in the model of open systems evolution, to minimise the negative impact of entropy upon the host environment of nature. To resolve the environmental problems caused by the unsustainable industrial pattern, the model of open system evolution is therefore proposed by the author as an alternative post-industrial pattern for environmental sustainability. 
In brief, the model of open system evolution in the Second Law of Thermodynamics provides a theoretical framework of sustainable design in the built environment. The order of open systems evolution, i.e. the compatible coexistence of an open system and its host environment after its evolution, can be interpreted as a sustainable symbiosis of buildings with the host environment of the natural ecosystems. This order can be realised by thermodynamically transferring energy, matter and information of buildings with the host environment of nature, using the mechanism of selforganising an internal structure of energy and resources consumption, optimising the distributions of energy and resource use in buildings over the life cycles of provision, production, transport and consumption.

\section{THE ART AND SCIENCE OF SUSTAINABLE ARCHITECTURE}

The paradigm of open systems evolution is a guiding principle in Nature that seems specifically designed for sustainability. Learning from Nature, several implications of open system evolutions in architecture are generalised in [45], including a holistic scheme for systematic sustainability in ecological architecture in the model of open thermodynamics systems for ecological architecture, and sustainability through evolutionary optimisation. In addition, two theoretical implications are outlined below. In brief, it is argued that sustainable design via an open system model is a synthesis of arts and sciences.

\subsection{An intelligent model for sustainable design}

In the paradigm of open systems evolution, an intelligent model for sustainable design in architecture is proposed as follows:

1. A system: an abstract method to study buildings as complex open systems, the configuration of which is embedded in the natural environmental context, imposing certain opportunities, constraints and limits for the optimisation of the environmental performance of a building.

2. An indicator: buildings would be designed as open systems, which are intelligently aware of their environmental impact and adapt their environmental performance to minimise negative environmental impact; all of the on-going process would be indicated by a quantitative index of entropy; this indicator would then suggest the possible direction of optimisation; this quantitative indicator is specifically defined regarding to the host context of nature, as stated in the model of open systems evolution.

3. A mechanism: in the mechanism of open systems evolution, buildings are designed to be able to adapt and optimise their environmental performances with minimal negative impact over their life cycles, to be environmental compatible to the host environment of the natural ecosystem.

4. A contextual definition: the concept of sustainable design is defined as an environmental compatibility between buildings as open systems with their natural context as the host environment, which can be achieved through complex environmental interactions between them through the mechanism of open systems evolution.

5. An on-going process: the primary goals of sustainable design, i.e. the efficiency of energy and resource consumption and the minimisation of negative environmental such as pollution emission are realised by an on-going dynamic evolution of buildings as open systems; buildings would be in an intelligence to be aware of the negative impacts, and to actively and positively adapt and optimise their performances with minimal impacts.

6. Generality in application: the strategy in the paradigm of open systems evolution is applicable not only in sustainable design in architecture, but also in sustainable development in general. 
The interrelation of a development and its contexts, e.g. environmental context, sociological context, economic context, cultural context, geographical context, etc., can be interpreted in terms of the interrelations of an open system and its host environment; thus, in the evolutionary mechanism of open systems, sustainable development can be achieved with minimal negative impacts upon the context.

\subsection{A design theory of contextual architecture}

The paradigm of open systems evolution can be generalised as a strategy of contextual design for sustainable symbiosis of architecture with nature. This design strategy is notionally entitled 'a design of contextual architecture'. Contextual architecture refers that buildings would be designed environmentally responsive to the natural context, and dynamically interactive with the natural environment for the optimisation of their environmental performances, which can be realised by information communication technologies. In the terms of information science, through 'pattern recognition and learning experience' in the paradigm of open systems evolution, it is possible to realise contextual architecture, where the morphological design language, the structure, the materials, the spatial organisation, the topology of energy and resources can all be environmentally responsive to their various contexts.

\section{CONCLUSION}

This paper proposes a post-industrial paradigm for sustainable architecture via an open system model. Sustainable architecture is configured as an open system whose environmental performance is adapted and optimised intelligently using the tools of information and communication technology in support of participation by the end-users, and employing the mechanisms of open systems evolution to minimise the negative environmental impact on the natural environment, and desirable order of sustainable architecture, i.e. a sustainable symbiosis of architecture with nature.

\section{ACKNOWLEDGEMENT}

The author would like to acknowledge the warm support from Professor Rob Evans, Director, VRL, NICTA at the University of Melbourne, for his patient refining this paper.

\section{REFERENCES}

[1] Oppenheimer, S., The Origins of the British: A Genetic Detective Story, Constable and Robinson: London, 2006.

[2] McDonough, W. \& Braungart, M., Cradle to Cradle: Remaking the Way We make Things, North Point Press: New York, 2002.

[3] Steele, J., Sustainable Architecture: Principles, Paradigms, and Case Studies, McGraw-Hill: New York, 1997.

[4] Dobson, A., Green Political Thought, Unwin Hyman: London, 1990.

[5] Stasinopoulos, P., Smith, M.H. et al., Whole System Design: an Integrated Approach to Sustainable Engineering, Earthscan Ltd.: London, UK, 2008.

[6] Hagan, S., Taking Shape: A New Contract between Architecture and Nature, Architectural Press: Oxford, 2001.

[7] Gauzin-Müller, D. \& Favet, N., Sustainable Architecture and Urbanism: Concepts, Technologies, Examples, Birkhauser: Basel; Boston, 2002.

[8] Salat, S., The Sustainable Design Handbook China: High Environmental Quality Cities and Buildings, Hermann Editeurs des Sciences et des Arts (CSTB), 2006. 
[9] Bisch, J., Natural metabolism as the basis for intelligent architecture. Construction Ecology: Nature as the Basis for Green Buildings, eds C.J. Kibert, J. Sendzimir \& G.B. Guy, Taylor \& Francis: New York, 2001.

[10] Wines, J., Green Architecture, Taschen: Köln; London, 2000.

[11] Moore, S., Architecture, Esthetics, and Public Health. The Hand and the Soul: Ethics and Aesthetics in Architecture and Art. S. Illescu. University of Virginia Press: Charlottesville, VA, 2006.

[12] Birkeland, J. (ed.), Design for Sustainability: A Sourcebook of Integrated, Eco-logical Solutions, Earthscan Publications Ltd.: London, Sterling, VA, 2002.

[13] Ray-Jones, A. (ed.), Sustainable Architecture in Japan: the Green Buildings of Nikken Sekkei, Wiley-Academy: Chichester, 2000.

[14] Daly, H.E., Ecological Economics and the Ecology of Economics: Essays in Criticism, E. Elgar: Cheltenham, UK; Northampton, MA, USA, 1999.

[15] Hawken, P., Lovins, A. \& Humter Lovins, L. et al., Natural Capitalism: Creating the Next Industrial Revolution, Earthscan: London, 1999.

[16] Rees, W.E. \& Wackernagel, M., Our Ecological Footprint: Reducing Human Impact on the Earth, New Society Publishers: Gabriola Island, BC, 1996.

[17] Commoner, The Environmental Cost of Economic Growth, 1972.

[18] Durning, A.T., How Much is Enough? The Consumer Society and the Future of the Earth, Earthscan: London, 1992.

[19] Steele, J., Ecological Architecture: a Critical History 1900-today, Thames \& Hudson: London, 2005.

[20] Walker, S., Sustainable by Design: Explorations in Theory and Practice, Earthscan: London; Sterling, VA, 2006.

[21] Brundtland, G.H., Our Common Future: The World Commission on Environment and Development, The Assessment of the Brundtland Commission, Oxford University Press: Oxford; New York, 1987.

[22] Docalavich, H., The UN and the Global Marketplace: Economic Developments, Mason Crest Publishers: Philadelphia, 2007.

[23] Jaynes, E.T., Probability Theory: the Logic of Science, Cambridge University Press: New York, 2003.

[24] Singleton, D., Sustainability, a Risk Management Perspective, Arup: London, UK, 2004.

[25] Allenby, B.R. \& Graedel, T.E., Defining the environmentally responsible facility. Measures of Environmental Performance and Ecosystem Condition, ed. P.C. Schulze, National Academy Press, National Academy of Engineering: Washington, DC, 1999.

[26] International Earth Science Information Network, 2005.

[27] Bellut, C., "Arh, Luise, lass...das ist ein zu weites feld," or: the Gordian knot of complexity. Complexity: Design Strategy and World View (Context Architecture), eds A. Gleiniger \& G. Vrachliotis, Birkhäuser: Basel, 2008.

[28] Prigogine, I. \& Stengers, I. Order Out of Chaos: Man's New Dialogue with Nature, Fontana Paperbacks: London, 1984.

[29] Jencks, C., The Architecture of the Jumping Universe: a Polemic: How Complexity Science is Changing Architecture and Culture, Academy Editions: London, 1997.

[30] Vrachliotis, G., Popper's mosquito swarm: architecture, cybernetics, and the operationalization of complexity. Complexity: Design Strategy and World View (Context Architecture), eds A. Gleiniger \& G. Vrachliotis, Birkhäuser: Basel, 2008.

[31] Erve van de, W.S., Le Corbusier, Idealistisch Architect, Oosthoek: Utrecht, 1951. 
[32] Gleiniger, A., The difficult whole or the rediscovery of complexity in architecture. Complexity: Design Strategy and World View (Context Architecture), eds A. Gleiniger \& G. Vrachliotis, Birkhäuser: Basel, 2008.

[33] Nicolis, G. \& Prigogine, I., Exploring Complexity: an Introduction, W.H. Freeman: New York, 1989.

[34] Ryn, S.V.D. \& Cowan, S., Ecological Design, Island Press: Washington, DC, 1996.

[35] Wines, J., The Art of Architecture in the Age of Ecology, Sustainable Architecture White Papers, Earth Pledge Foundation: New York, 2000B.

[36] Portoghesi, P., Nature and Architecture, Skira Editore S.P.A.: Milano, Italy, 2000.

[37] Venturi, R., Context in architectural composition, excerpts from M.F.A thesis, Princeton University (1950). Complexity-design Strategy and World View (Context Architecture), eds A. Gleiniger \& G. Vrachliotis, Birkhäuser: Basel, 2008.

[38] Knowles, R.L., Ritual House: Drawing on Nature's Rhythms for Architecture and Urban Design, Island Press: Washington, DC, 2006.

[39] Venturi, R., Complexity and Contradiction in Architecture, Butterworth Architecture: London; Sydney, 1988.

[40] Gleiniger, A. \& Vrachliotis, G. (eds), Complexity: Design Strategy and World View (Context Architecture), Birkhäuser: Basel, 2008.

[41] Castrigiano, D.P.L. \& Hayes, S.A., Catastrophe Theory, Addison-Wesley Pub. Co., Advanced Book Program: Reading, MA, 1993.

[42] Lovelock, J., The Revenge of Gaia: Why the Earth is Fighting Back - and How We Can Still Save Humanity, Allen Lane: London, New York, 2006.

[43] Von Neumann, J., Theory of Self-reproducing Automata, University of Illinois Press: Urbana, 1966.

[44] Mclennan, J.F., Living Buildings, Sustainable Architecture White Papers, Earth Pledge Foundation: New York, 2000.

[45] Gu, Y. \& Evans, R., An open system model of ecological architecture. Eco-Architecture III, Harmonisation between Architecture and Nature, eds S. Hernandez, C.A. Brebbia \& W.P. de Wilde, Wessex Institute of Technology Press: UK, ISBN: 9781845644307, ISSN 1746448X (print), 17433541 (online), April 2010.

[46] Huber, P. \& Mills, M.P., The Bottomless Well: the Twilight of Fuel, the Virtue of Waste, and Why We Will never Run Out of Energy, BasicBooks: New York, 2006.

[47] Rogers, E.M., Physics for the Inquiring Mind; the Methods, Nature, and Philosophy of Physical Science, Princeton University Press: Princeton, NJ, 1960. 